\title{
Seeking Competitive Advantage Through Platform-Enabled Resources: The Case of Food Delivery Platforms
}

\author{
Joaquin Rodriguez \\ Louisiana State University \\ jrod122@1su.edu
}

\author{
Gabriele Piccoli \\ Louisiana State University \\ gpiccoli@,cct.lsu.edu
}

\begin{abstract}
As digital platforms become increasingly ubiquitous, firms in a wide array of industries face the decision of whether to join them and how to compete within them. The information systems field is in a unique position to theorize and investigate how platform participants can use broadly available digital platform resources in order to achieve, and possibly sustain, competitive advantage. We empirically investigate the theoretical proposition that restaurants joining the food delivery digital platform can compete by leveraging a specific emergent capability we call platform-fulfillment capability. Our results indicate that differentiation and competitive advantage are possible, even though all platform participants have access to the same digital platform resources. This result has important implications for the evaluation of digital platform strategies by organizations that are increasingly dependent on the use of digital technology.
\end{abstract}

\section{Introduction}

Almost two decades after the publication of the controversial article "IT Doesn't Matter," [8] the Information Systems field is again challenged to understand and explain the phenomenon of sustainable competitive advantage. While examples abound of firms that have been able to maintain superior financial performance over time, the role that digital technologies play in the process is not systematically understood. Moreover, there is a new element in the search for sustained superior competitive performance through IS: digital platforms. Today, several of the largest corporations in the world are platform owners (e.g., Microsoft). Furthermore, digital platform dynamics are central to the emergence of startups that are disrupting traditional sectors, such as finance (e.g., Revolut) and last-mile delivery (e.g., Postmates).
While there is a burgeoning literature showing how digital platforms owners can leverage their central position into a sustainable competitive advantage [3, $13,15,39]$, there has been limited attention devoted to the competitive struggle of platform constitutive agents - those firms who join the platform but do not control it. A few firms (e.g., Apple, Google, Amazon) are garnering the bulk of research attention.

Specifically, little work to date has focused on understanding whether and how those firms that join a digital platform that they do not own or control, can achieve a position of competitive advantage versus the other platform participants. Notable studies that adopt the perspective of platform constitutive agents include the analysis of the competitive dynamics between platform owners and its participants $[15,43]$, the cost of multihoming by platform participants [10], the interplay between internal and external architecture and its effects on competitive advantage [38], and the co-creation of value between platform owners and platform participants [9].

We argue that the majority of organizations the IS community serves with its research are not platform owners. Instead, it is largely the constitutive agents who, as they are increasingly dependent on the use of digital technology to enable their business models, processes, and offerings, become dependent on digital platforms that they do not own or control.

We define a digital platform as an evolving sociotechnical artifact that: (1) federates and coordinates constitutive agents to facilitate digital innovation; (2) creates value by enabling economies of scope in supply and/or demand; and (3) has the structure of a digital layered modular architecture with both a core and a periphery. This definition consolidates extant research that uses terms such as digital platform, technology platform, platform-mediated markets, or software-based platform interchangeably and often without explicit definition (Table 1).

As suggested by recent literature, digital platforms can significantly influence the financial, strategic and organizational performance of its participants [14, 31]. 
These dynamics are relevant well beyond the technology sector. Traditional businesses are increasingly forced to craft "digital platform strategies" in order to thrive or even survive. Restaurants must leverage food delivery platforms [25], retailers must compete within Amazon marketplace or Alibaba [18], entertainment companies must be attentive to platform dynamics in gaming platforms or content streaming services.

This study extends the business value of IT (BVIT) [27] literature to the context of digital platforms. Similarly to IT assets [29], digital platforms are generally available to competing firms. Thus, we investigate whether and how organizations can achieve and sustain competitive advantage from the use of "commoditized" and widely available digital platform resources. We do so within the paradigm of application level research [33, 36]. Thus, we take as the unit of analysis the competitive moves [33] or resources [29] that result from the combination of digital platform capabilities with other organizational resources. We investigate the increasingly popular and non-traditional IS context of food delivery, where restaurants are faced with the decision of whether or not to join digital platforms (e.g., GrubHub). The context of our study is important because it enables us to clearly separate the firm's value proposition providing a dining experience to patrons - from the use of digital resources. This separation is not as clear in much of the literature where the product is itself digital (e.g., video games, software development). Thus, compatibly with our theoretical lens, the focus of the analysis and the enabler of competitive advantage we investigate is not the digital technology per se. Rather, it is the emergent IT-enabled resources that the firm can create by leveraging the assets and capabilities exposed by the digital platform [29, 33]. In the context of our study we conceptualize and investigate a specific emerging resource called: platform-fulfillment capability. As we theorize below, such capability enables restaurants to offer superior customer service that leads to a competitive advantage in the form of high visibility in the platform's marketplace. The theorized competitive advantage is theoretically sustainable. However, this hypothesis cannot be tested at the current stage.

Our research offers four main contributions. First, we provide clarity to the concept of digital platform and theorize the role of platform resources in enabling platform participants who seek competitive advantage. Second, we empirically investigate the differential effect of pursuing the same platform enabled strategic initiative in different organizations. Third, we explore the emergence of platform-enabled resources by examining the variability in the performance of different strategic initiatives. Finally, we challenge the view that considers widely available digital platforms as commodities unable to drive sustainable competitive advantage.

\section{Digital Platforms}

Efforts to uncover the mechanisms that link platform adoption to competitive advantage [10, 38], are constrained to the context of software development (e.g., app or videogames development). As "software is eating the world" [2], we increasingly observe a number of digital platforms that reside outside the realm of software development and technology products. These digital platforms contribute to changing the competitive landscape for all of the firms in the industries they impact. For example, the Facebook platform is increasingly popular in the context of customer engagement, while the Amazon Marketplace Web Service (MWS) platform is an enabler of enhanced customer service in the Amazon Marketplace. Furthermore, digital platforms such as Shopify, enable organizations to create an online store, while also managing cross platform integrations (e.g., Facebook and Amazon Marketplace) and product fulfillment without the need to develop software applications. More importantly from a research perspective, the academic IS literature on digital platforms prevalently assumes the point of view of platform owners (e.g., Apple). As a consequence, our understanding of the dynamics that lead to the adoption of, and competitive success within, digital platform is still relatively under researched [26, 35].

Summarizing and consolidating previous literature (Table 1) the definition we advance in the introduction offers a number of insights. First, it clarifies the nature of digital platforms not as purely technical or organizational artifacts, but as socio-technical systems. Thus, it embodies the socio-technical perspective that characterizes the information systems discipline giving equal importance to the social and technical elements of the artifact [37]. Second, it identifies the organizational components of digital platforms, stressing the "federated" and "coordinated" relationships that platforms create with ecosystem players to facilitate digital innovation. Therefore, constitutive agents of the platform are influenced by the objectives of the platform owner and internalize them through various forms of coordination aimed at achieving common goals. Third, it specifies the economic characteristics of digital platforms. The definition requires that value creation mechanisms include the creation or leverage of economies of scale and/or scope. Fourth, it specifies the layered and 
modular architecture of digital platforms which not only refers to the technical elements of the system, but also to its social and organizational architecture.

\section{Table 1. Platform conceptualizations in academic research}

\begin{tabular}{|c|c|}
\hline Author & Definition \\
\hline $\begin{array}{l}\text { Gawer, } 2014 \\
{[16: 1240]}\end{array}$ & $\begin{array}{l}\text { Technology platforms are } \\
\text { "evolving organizations or } \\
\text { metaorganizations that: (1) federate } \\
\text { and coordinate constitutive agents } \\
\text { who can innovate and compete; ( } 2 \text { ) } \\
\text { create value by generating and } \\
\text { harnessing economies of scope in } \\
\text { supply or/and in demand; and ( } 3 \text { ) } \\
\text { entail a technological architecture } \\
\text { that is modular and composed of a } \\
\text { core and a periphery." }\end{array}$ \\
\hline $\begin{array}{l}\text { Tiwana, } 2018 \\
\text { [38:2] }\end{array}$ & $\begin{array}{l}\text { A platform refers to "an extensible } \\
\text { technological foundation used by } \\
\text { complementary, functionality- } \\
\text { augmenting apps" }\end{array}$ \\
\hline $\begin{array}{l}\text { Tiwana et al., } \\
2010 \text { [39:675] }\end{array}$ & $\begin{array}{l}\text { Software-based platforms are } \\
\text { defined as "the extensible codebase } \\
\text { of a software-based system that } \\
\text { provides core functionality shared } \\
\text { by the modules that interoperate } \\
\text { with it and the interfaces through } \\
\text { which they interoperate" }\end{array}$ \\
\hline $\begin{array}{l}\text { Constantinides } \\
\text { et al., 2018 } \\
{[12: 381]}\end{array}$ & $\begin{array}{l}\text { Digital platforms are defined as "a } \\
\text { set of digital resources-including } \\
\text { services and content-that enable } \\
\text { value-creating interactions between } \\
\text { external producers and consumers" }\end{array}$ \\
\hline $\begin{array}{l}\text { Parker et al., } \\
2017 \text { [30:256] }\end{array}$ & $\begin{array}{l}\text { A platform is a "layered } \\
\text { architecture of digital technology, } \\
\text { combined with a governance } \\
\text { model" }\end{array}$ \\
\hline $\begin{array}{l}\text { Eisenmann et } \\
\text { al., } 2011 \\
{[13: 1270]}\end{array}$ & $\begin{array}{l}\text { Platform-mediated markets are } \\
\text { markets "where users' interactions } \\
\text { with each other are subject to } \\
\text { network effects and are facilitated } \\
\text { by a common platform provided by } \\
\text { one or more intermediaries" }\end{array}$ \\
\hline
\end{tabular}

It is important to note that the literature often uses the terms digital platform interchangeably with the term marketplace. The confusion likely stems from the fact that many dominant digital platforms also control a marketplace (e.g., iOS and its relative AppStore). However, in the context of online transactions, marketplaces are "communities of buyers and sellers who exchange product information, coordinate, and transact using Internet technologies." [32:40] Thus, although often related, in our context, digital platforms are the socio-technical systems that provide the resources that platform constitutive agents use to pursue digital innovation. Conversely, a marketplace is the digital space where the innovations that the digital platform facilitates are exchanged between buyers and sellers. Shopify and Stripe are two of many examples of digital platforms that do not operate a marketplace.

\section{Theoretical Framework}

The Information Systems literature defines the business value of IT (BVIT) as "the organizational performance impacts of information technology at both the intermediate process level and the organization-wide level, comprising both efficiency and competitive impacts." [27:287] The BVIT stream of research is grounded in the Resource Based View of the firm (RBV) [5, 24, 27] and considers organizational resources as the basis of firms' competitive action. Organizational resources are any tangible or intangible asset or capability that companies own, control, or have access to on a semipermanent basis $[19,33]$. With assets being "anything tangible and intangible the firm can use in its processes for creating, producing, and/or offering its products (goods or services) to a market" [41:109]. Capabilities are defined as "repeatable patterns of actions in the use of assets to create, produce, and/or offer products to a market." [41:109]

The RBV treats organizational resources as the building blocks of firm strategy and posits that the source of a firm's competitive advantage is to be found in organizational resources that are valuable, rare, inimitable, and non-substitutable [4].

As a consequence, a major limitation of the RBV when applied to strategic information systems is that it neglects resources that lack those four characteristics, such as commodity IT assets or widely available digital platform resources [6, 33]. Empirical and theoretical contributions to the IS literature show how considering resources as isolated elements of competitive advantage results in both conceptual and measurement fallacies (e.g., productivity paradox). In fact, as many organizational resources are emergent systems [29], attempting to analyze the value of their components in isolation may be unproductive and yield flawed conclusions $[11,17]$.

\subsection{Platform-enabled Resources}


Digital platform resources are widely available to all constitutive agents (i.e., firms competing with the platform). Thus, many would argue that they do not present strategic potential for the organizations joining the platform. We differ, as theorized below. Digital platform resources are those assets and/or capabilities that digital platforms owners create and make available to platform users to facilitate their digital innovation. For example, Shopify's integration with Amazon Marketplace and Instagram is a platform capability that enables retailers who join Shopify's platform to seamlessly manage their inventories across multiple marketplaces. When a digital platform resource interacts with resources of the constitutive agents, we observe the emergence a of subsystem: platform-enabled resource.

Platform-enabled resources can assume emergent properties [21, 42] that arise from the relationship between the components of the subsystem, yielding a resource that is "greater than the sum of its parts." [29:173] When the emergent properties produce positive outcomes, the relationship between the digital platform and organizational resources is synergistic [29]. However, to realize this potential synergy, the firm must ensure that the digital platform resources are properly combined with organizational resources [29]. As a consequence, synergy is positively influenced by both: (1) the ability of a constitutive agents to leverage the digital platform resources in its regular activities and routines along with its own organizational resource - termed compatibility [29]; (2) the actions of the constitutive agent to implement the digital platform resources in combination with the organizational resource - termed integration effort [29:173].

High synergy between the digital platform resources and organizational capabilities of the platform participant positively impacts the strategic potential of the emerging platform-enabled resource, where strategic potential is defined as the ability to "enable a firm to conceive of and implement strategies that improve its efficiency and effectiveness" [4:102]. Therefore, it is the emerging platform-enabled resource, and not the digital platform resources, that can achieve a strategic potential when it is valuable, rare, and inimitable.

\subsection{The Differential Synergy of Platform- enabled Resources}

From the notion of emerging resources follows that the same digital platform resources will have different effects and outcomes in heterogenous organizations [29]. Our research uses the notion of brand to investigate the strategic potential of platform-enabled resources. Brands "reflect the complete experience that customers have with products" [23:740]. Particularly for multi-unit operations (e.g., restaurant chains), the brand represents both the firm assets (e.g., IT systems) and operating procedures (e.g., business processes). Thus, brand consistency across different locations is critical to preserve a homogeneous customer experience. In fact, brand parents engage in quality assurance and other compliance mechanisms that different brand locations offer a consistent customer experience. For example, McDonald's invests a considerable amount of resources to standardize both the physical environment and food quality of its franchisees.

The brand, therefore, represents a proxy for firm's complementary resources that includes both organizational assets (e.g., standardized IT assets) and capabilities (e.g., standardized processed). Thus, the combination of organizational resources with the same digital platform resources for firms affiliated with different brands will produce variations in the synergy of the resulting platform-enabled resource [29].

H1.1: There are significant between-brand variations in platform-enabled resource synergy.

Organizations that belong to the same brand are constrained by the brand's organizational resources. However, it is the purposeful management effort to combine organizational resources, that results in the emergence of a platform enabled resource and, in turn, differential firm performance $[1,22,28]$. As a consequence, we posit that different levels of integration efforts within organizations that share the same organizational resources will also produce variations in synergy levels of the emerging platformenabled resource [29].

H1.2: There are significant within-brand variations in platform-enabled resource synergy.

\subsection{Platform-enabled Resource and Competitive Advantage}

Organizations enjoy a competitive advantage when they implement initiatives that are unavailable to competitors. The competitive advantage is sustained when competitors are unable to replicate the same initiative [4]. In keeping with recent theorizing [29] we adopt a system theory perspective., Thus contrarily to traditional RBV research, we do not evaluate the strategic potential of the digital platform resources in isolation. Rather, we focus on the strategic potential of the emergent platform-enabled resource - restaurants 
platform-fulfillment capability in our context - that results from the purposeful combination by the constitutive agents of the widely available digital platform resources and their own organizational resources. It is when the emergent platform-enabled resource assumes valuable, rare, inimitable, and nonsubstitutable characteristics that it becomes a source of competitive advantage [29]. Thus, when the synergy between the organizational resource and the digital platform resource is greater, we expect that the emerging platform-enabling resource assumes a higher strategic potential.

H2.1: Greater synergy between a digital platform resource and an organizational resource positively affects the strategic potential of the platform-enabled resource.

\section{Food Delivery Digital Platforms}

Although food delivery is not a novel concept, advancements in digital technology are driving the disruption of well-established dynamics in the food industry. Despite food delivery still being dominated by the traditional model of phone orders and restaurant deliveries, food providers are increasingly challenged by the emergence of innovative ordering experiences and delivery methods that are driving substantial channel migration. In 2020, online-enabled delivery is expected to reach around $60 \%$ of the market, up from less than $10 \%$ from a decade earlier [44]. Thus, as digital platforms rise to prominence, restaurants face both opportunities and threats. An important factor driving online channel migration is the emergence of food delivery digital platforms, such as UberEats, GrubHub, and Deliveroo, that facilitate the ordering experience and the delivery process.

Food delivery digital platforms (from now onwards referred to as delivery platforms) are evolving socio-technical systems that provide restaurants with resources that facilitate the offering of "home dining experiences." They enable alternative ways to meet the customers" "job to be done" [40] of satisfying their hunger in a convenient, affordable, and consistent manner without having to leave home. Traditionally, only a limited number of players had the scale and resources to provide a reliable delivery service (e.g., Domino's Pizza). Conversely, equipped with the key resources made available by delivery platforms, an increasing number of restaurants can offer a "home dining experience" to their patrons. For example, delivery platforms equip restaurants with digital assets to successfully manage the fulfillment of orders. Furthermore, delivery platforms provide a fleet of riders who carry the food to the customer's home. Thus, driven by advancements in technology, delivery platforms increase the feasibility, and consequently the popularity of home delivery dining experiences. Digital platforms, such as GrubHub and JustEat, meet all the elements of our definition of digital platforms.

1. They are socio-technical artifacts. For example, when a restaurant uses the UberEats platform, the interaction involves both the use of technology, and the acceptance of the governance terms that UberEats imposes (e.g., resolution of customer complains);

2. They federate and coordinate the numerous restaurants that join the platform. For example, during peak hours Deliveroo needs to coordinate its limited number of riders to provide a consistent delivery opportunity to all constitutive agents. Thus, restaurants that are unable to fulfill the orders in the expected time frame are relegated to lower positions in the Deliveroo marketplace.

3. They facilitate digital innovation. For example, the JustEat digital food delivery platform empowers restaurants to a) adopt different menu strategies (i.e., product innovation), b) offer reliable home delivery without having to hire drivers (i.e., process innovation), and c) diversify revenue strategies by seeking incremental sales beyond dine-in patrons (i.e., business model innovation);

4. They have a layered modular architecture comprised of a core and a periphery. For example, UberEats core optimizes and coordinates the delivery times and routes in real-time, while restaurants leverage the platform interfaces at the periphery (e.g., Menu design) to manage their offerings.

Restaurants today face the important decision of whether to join one or more food delivery platforms (i.e., become constitutive agents of these platforms). Upon deciding to join, restaurants must strategize how to create and possibly sustain a competitive advantage in a context where the same digital platform resources are available to all other restaurants in the market. We posit that the competitive dynamics are dictated by restaurants' organizational resources, compatibility, and integration efforts, which lead to differentiated platform-enabled resources and, consequently, differential performance.

\section{Methodology}

In this study, we utilize an archival research methodology. The context is the restaurant sector 
where delivery platforms enable the implementation of a food delivery strategic initiative. Our primary data source is a European delivery platform (named here: FoodNow). FoodNow is a market leader in several European markets and has rapidly increased its popularity in terms of both end-customers (i.e., diners) and restaurants joining the platform over the past five years. FoodNow provides the resources, such as a menu management system and a fleet of drivers, that enable restaurants to offer food delivery services. Furthermore, like most digital platforms, FoodNow also controls a marketplace where customers (i.e., diners) can discover restaurant offerings, place orders and pay. FoodNow adopts a strategy where the digital platform and the marketplace are closely integrated. Restaurants that join FoodNow are required to use the digital platform resources to configure and manage their marketplace offerings. For example, restaurants can launch promotions for specific days of the week.

Integration efforts by the restaurant are visible on FoodNow's website, thus allowing us to infer restaurants competitive moves from different activities in the marketplace. For example, when a restaurant activates the "Busy Mode" using the platform capability, a banner in the restaurant's page in the marketplace communicates to customers about potential delays with their order.

We gather daily data from all restaurants associated with the biggest chains by number of restaurants in London (UK). We analyze all chains with more than 70 restaurant locations in the delivery platform. London was selected for this study as it is representative of a city with a high number of restaurants and multiple food delivery platforms. Thus, we consider London as representative of a competitive and dynamic market. Furthermore, by focusing on one city we reduce market specific confounds such as wages, weather, or other local idiosyncrasies.

We scrape data from the marketplace at regular intervals. The following analysis draws on restaurant information collected from the platform marketplace five times per day over a period of 30 days during June 2019 (168,448 total observations). ${ }^{1}$ Considering a timeframe of 30 days improves reliability of results as it eliminates variability caused by non-recurrent events (e.g., understaffed shifts) or day of the week (e.g., restaurants that are busier during week or weekend days). Furthermore, we consider only those neighborhoods of the greater London with more than 100 restaurants. Therefore, we exclude from the analysis those neighborhoods with a scarce level of competition between restaurants.

\footnotetext{
${ }^{1}$ Data collection is ongoing.
}

Table 2. Summary statistics dataset

\begin{tabular}{|l|l|}
\hline Number of chains & 14 \\
\hline Number of restaurants & 544 \\
\hline Number of observations & 168,448 \\
\hline
\end{tabular}

\subsection{Measures}

When joining the delivery platform, restaurants have access to a number of platform resources that facilitate the implementation of a food delivery capability. In this research we focus on the interplay between the restaurants' order fulfillment organizational capability and FoodNow's order management platform resources. When restaurants integrate the digital platform resources with their organizational resource, theory predicts the emergence of an outside-in [41] platform-fulfillment capability. The greater the compatibility and management's integration effort, the greater the synergy between the digital platform resource and the organizational resources. A greater synergy positively impacts, the strategic potential of the platform-enabled resource. It follows that synergy and strategic potential should be measured at different levels [29]. Synergy reflects positive impacts on the organizational resource, whereas strategic potential reflects benefits to the firm.

Consistent with the Nevo and Wade model [29] we conceptualized the platform-fulfillment capability as the emergent resource that enables a restaurant to effectively fulfill customers' orders. Effective fulfillment happens when food delivery is timely and accurate. Thus, when the relationship between the digital platform and organizational resource is synergistic, we theorize that restaurants will display superior order fulfilling performance - as measured by order delivery time and restaurants' rating. Order delivery time is the amount of time the restaurant commits to deliver the order once it is confirmed. The restaurants' rating score is a marketplace specific measure of customer satisfaction with the restaurant. The marketplace only allows customers to provide a review score after completing an order.

We posit that a high synergy with the platform resources is positively associated to low delivery times and high customer ratings. Specifically, to obtain a measure that accounts for competitors' level of performance, we compute the speed of delivery of a restaurant relative to the average delivery speed for all 
restaurants that deliver to the same neighborhood. Similarly, we compute the rating score relative to the average rating score of all restaurants delivering to the same neighborhood. When a restaurant achieves high synergy, we expect that its relative time of delivery is lower than the average time of delivery of its competitors and their relative customer rating is higher than competitors'. In other words, we provide a first test of theory predicting that the platform capability yields a positive impact on organizational resources [29]. Finally, we posit that a high synergy impacts the strategic potential of the organization by improving the ranking position of the restaurant in the delivery marketplace.

\subsection{Data Analysis and Results}

We use a mixed-effect model to control for brand and restaurants systematic variations. We used a stepwise approach by first modeling the empty model to split the variance between the brand and restaurant levels (Model 1). We then add control variables to the empty model (Model 2). Finally, we add the two independent variables, one at the time (Model 3 and 4). We specify a mixed-effects model using the lme4 R package (version 1.1-21):

$Y_{i j t}=\alpha_{000}+\beta_{1} N R_{i j t}+\beta_{2} P I_{i j t}+\beta_{3} M P_{i j t}+\beta_{4} M I_{i j t}+$ $\beta_{5} D_{i j t}+\beta_{6} R_{i j t}+V_{00 t}+U_{0 j t}+R_{i j t}$

Where $Y_{j k i}$ represents standardized ranking position of restaurant $j$ belonging to brand $k$ at time $t$; $\alpha_{00}$ is the grand ranking mean; $\beta_{2}, \beta_{2}, \ldots, \beta_{6}$ denote the coefficients for all variables; NR denotes number of restaurants, PI number of popular (highly requests by customers) items on the menu, MP average menu price, MI number of items in the menu, D relative time of delivery, and $\mathrm{R}$ relative rating score.

We investigate H1.1 and H1.2 modeling the empty model of the mixed multilevel analysis. Multilevel analysis models nest units of analysis, such as restaurant affiliated with a brand [7]. Each restaurant is nested within a brand and a brand includes multiple restaurants. We use a 3-level model in order to identify the variance related to the restaurants (Level 1) and to the brands (Level 2). Level 3 captures repeated measures variability of the panel data. This technique has been used both in management [20], and in IS research [34].

The results support both H1.1 and H1.2. Of the total variance of ranking position, $43.6 \%(0.2542 /$ $(0.2542+0.2109+0.1176))$ is situated at the chain level, whereas 36.2\% (0.2109/ (0.2542+0.2109+ $0.1176)$ ) is situated at the restaurant level. The level- two intraclass correlation coefficient is estimated at 0.547 . Thus, the brand level contributes slightly more to the variability of ranking positioning in the marketplace than the restaurant level. However, both brand and restaurant variables are significant and present high intraclass correlations. These results indicate that, as hypothesized, there are significant between brand variations (H1.1) and significant within brand variations (H1.2) in the ranking positioning of restaurants, which we consider as a proxy of the strategic potential of the initiative.

Table 3. Results of mixed-effects models

\begin{tabular}{|l|l|l|l|}
\hline Variable & M2 & M3 & M4 \\
\hline NR & $-4.821 \mathrm{e}-05$ & $-6.89 \mathrm{e}-05$ & $-4.19 \mathrm{e}-05$ \\
& $(9.165 \mathrm{e}-$ & $(8.61 \mathrm{e}-06)$ & $(0.234)$ \\
& $06)$ & & \\
\hline PI & 0.21 & 0.205 & 0.193 \\
& $(0.033)$ & $(3.30 \mathrm{e}-02)$ & $(0.032)$ \\
\hline MP & -0.068 & -0.067 & -0.064 \\
& $(0.026)$ & $(0.025)$ & $(0.024)$ \\
\hline MI & $-5.161 \mathrm{e}-04$ & $-6.36 \mathrm{e}-04$ & $-6.86 \mathrm{e}-04$ \\
& $(8.523 \mathrm{e}-$ & $(8.29 \mathrm{e}-04)$ & $(7.94 \mathrm{e}-04)$ \\
& $04)$ & & \\
\hline $\mathrm{D}$ & & -0.003 & -0.003 \\
& & $(2.29 \mathrm{e}-05)$ & $(2.29 \mathrm{e}-05)$ \\
\hline $\mathrm{R}$ & & & 0.012 \\
& & & $(6.53 \mathrm{e}-04)$ \\
\hline Constant & 0.258 & 0.273 & 0.327 \\
& $(0.251)$ & $(0.243)$ & $(0.234)$ \\
\hline Deviance & $142082^{* * *}$ & $121148^{* * *}$ & $120804 * * *$ \\
\hline $\begin{array}{l}\text { Variance } \\
\text { restaurant }\end{array}$ & 0.293 & 0.277 & 0.254 \\
\hline $\begin{array}{l}\text { Variance } \\
\text { chain }\end{array}$ & $0.242)$ & $(0.526)$ & $(0.504)$ \\
\hline
\end{tabular}

Notes: ${ }^{*} \mathrm{p}<0.05, * * \mathrm{p}<0.025, * * * \mathrm{p}<0.001$

We test H2.1 using a mixed effect model to control for brand and restaurants systematic variations. The standardized ranking positioning assumes values between -3 and 2 , where 3 is a top ranking in the marketplace, and thus corresponds to high visibility. Table 3 presents the results of our analysis. The results show that the number of restaurants competing in the same neighborhood is negatively related to ranking $(\beta$ $=-4.19 \mathrm{e}-05)$. The number of popular items in the menu, is positively related to ranking $(\beta=0.193)$. The average price of the menu is negatively related to ranking $(\beta=-0.064)$. The number of items in the menu is negatively associated with ranking $(\beta=-6.86 e-04)$. The relative speed of delivery is negatively associated with ranking ( $\beta=-0.003)$. Finally, the relative rating score is positively associated with ranking $(\beta=0.012)$. Therefore, we find that after controlling for brand and 
restaurant effects, number of competitors, menu average price, number of popular menu items, and total number of menu items: (1) a relative decrease of delivery time is associated with an improvement of ranking in the marketplace; (2) a relative increase in customer rating is associated with an improvement of ranking in the marketplace. Thus, we find support for $\mathrm{H} 2.1$.

\section{Discussion}

Our empirical study contributes to the stream of research on the business value of IT in the increasingly important context of digital platforms. As digital platforms become ubiquitous and increasingly tailored for specific business and/or customer needs (e.g., food delivery), organizations are faced with two important decisions: whether or not to join the platform and what digital platform strategies to implement.

Our results support the theoretical proposition that digital platform resources foster the emergence of platform-enabled resources that have the potential to influence organizations' competitive position. Organizational resources, as proxied by the brand construct in our study, significantly influence the level of synergy achieved by the firm. However, our results indicate that brand affiliation only partially explains the differences in realized synergy between restaurants. Thus, even when different firms (i.e., restaurants) have similar resources, our results suggest that firm level actions have significant effects on realized synergy. In other words, integration efforts exerted by the management of each individual restaurant, most significantly influence synergy. Taken together, these results suggest that despite differences in brand-wide organizational resources between the competing restaurant chains, significant variability in realized synergy is to be found at the individual restaurant level. Thus, our results confirm that restaurants can achieve significantly different levels of synergy when integrating similar organizational resources with indistinguishable digital platform resources. In other words, platform constitutive agents can indeed differentiate amongst each other and achieve competitive advantage, despite all having access to the same platform resources made available by the digital platform.

A second finding of our research is that the restaurants relative delivery time and relative rating score influences the strategic position of the organization. More specifically, restaurants that are able to successfully integrate the digital platform resources within their organizational resources develop a superior platform-fulfillment capability that impacts their marketplace ranking visibility. Our results show how a superior platform-fulfilment capability positively influences the restaurants competitive advantage.

While preliminary, these results suggest that platform participant can successfully differentiate when competing in digital platforms they neither own nor control. That is, platform constitutive agents that achieve higher synergy between the digital platform and its organizational resources can implement platform-enabled strategic initiatives that can act as a source of competitive advantage. As a consequence, organizations that are unwilling to invest resources in integrating with the digital platform are unable to successfully compete.

Our work, while admittedly preliminary, presents the basis for future research that investigates the sustainability of digital platform strategies. We argue that the information systems field is best positioned to uncover the distinctive dynamics inherent to the "digital" of digital platforms. A number of future research opportunities stem from this realization.

\section{Limitations and Future Research}

As with any archival research effort, our study presents limitations that should be acknowledged when evaluating the contribution at its current stage. The use of archival data presents both strengths and weaknesses. The gathering of information from a major digital platform allows us to test our hypothesis for a large number of restaurants, thus increasing the reliability of our results. However, our measures are constrained by the restaurant's information publicly available in the digital platform's marketplace. As a consequence, we are unable to tease out the specific organizational resources that define the brand construct from those that may be restaurant specific. While we make the sensible assumption of standardization of organizational resources across brand affiliated restaurants, we are unable to evaluate the impact on the platform-enabled resource of different organizational resources configurations. In fact, it can be argued that there could also be significant organizational resources differences between restaurants of the same chain. A promising future avenue of research is the investigation, through mixed methods, of the dynamics that lead to the formation of the platform-enabled resources. In fact, our study demonstrates that it is possible to achieve superior synergy and strategic differentiation through the integration of widely available digital platform resources. It follows that, as predicted by Nevo and Wade [28, 29], compatibility and integration efforts are critical to the emergence of platform-enabled resources. Uncovering the specific integration 
mechanisms available to digital platform participants and explaining why they work is a promising avenue for future work. Such a theory of digital platform compatibility and integration would be of theoretical importance as well as a significantly contribution to practice.

Another limitation of the current research is the limited timeframe and number of restaurants evaluated. While data collection is ongoing and this limitation will soon be overcome, at the current stage, we are unable to determine the sustainability of competitive performance of the firms in our sample. Extending the data gathering to all restaurants over an extended period of time will allow for longitudinal studies that can advance our understanding of the sustainability of the superior synergy levels and its long-term impact on organizational performance. We identify two promising avenues related to the longitudinal perspective of our study. First, we could analyze the variations of realized synergy over time and its impacts on sustainable competitive advantage. This would enable improved understanding of the casual link between synergy and sustainable advantage in order to uncover the defensibility and learning dynamics over time. Second, we could investigate the commonalities of firms that exit the digital platform - those who decide to terminate their platform strategy. Studying those digital platform participants who forego the use of platform resources would enable the study of the causes that lead to the unsuccessful implementation of the platform-enabled strategic initiatives.

More fundamentally, the overarching theme of the work reported in this paper, as well as the future research we advocate, is to open the digital platform "black box" to uncover the dynamics that are distinctive to these emerging socio-technical artifacts and understand how increasingly pervasive digital technology changes the phenomena of strategic positioning and the pursuit of sustainable competitive advantage.

\section{References}

[1] Anderson, P., "Perspective: Complexity Theory and Organization Science”, Organization Science 10(3), 1999, pp. 216-232.

[2] Andreessen, M., "Why Software Is Eating the World", Wall Street Journal 20(2011), 2011, pp. C2. (accessed 2019-07-15)

[3] Bakos, Y., and E. Katsamakas, "Design and ownership of two-sided networks: Implications for Internet platforms", Journal of Management Information Systems 25(2, SI), 2008, pp. 171-202.
[4] Barney, J., "Firm resources and sustained competitive advantage", Journal of management 17(1), 1991, pp. 99120.

[5] Bharadwaj, A.S., "A resource-based perspective on information technology capability and firm performance: an empirical investigation", MIS quarterly, 2000, pp. 169196.

[6] Bharadwaj, A.S., P.R. Varadarajan, and J. Fahy, "Sustainable competitive advantage in service industries: A conceptual model and research propositions", Journal of Marketing 57(4), 1993, pp. 83-99.

[7] Bryk, A.S., and S.W. Raudenbush, Hierarchical Models: Applications and Data Analysis Methods, Newbury Park, CA: Sage, 1992.

[8] Carr, N.G., "IT Doesn't Matter", Harvard Business Review, 2003. https://hbr.org/2003/05/it-doesnt-matter. (accessed 2019-07-15)

[9] Ceccagnoli, M., C. Forman, P. Huang, and D.J. Wu, "Cocreation of Value in a Platform Ecosystem: The Case of Enterprise Software", MIS Quarterly 36(1), 2012, pp. 263290.

[10] Cennamo, C., H. Ozalp, and T. Kretschmer, "Platform Architecture and Quality Trade-offs of Multihoming Complements", Information Systems Research 29(2), 2018, pp. 461-478.

[11] Checkland, P., "Systems Thinking”, Rethinking Management Information Systems, 1999, pp. 45-56.

[12] Constantinides, P., O. Henfridsson, and G.G. Parker, "Platforms and Infrastructures in the Digital Age", Information Systems Research 29(2), 2018, pp. 381-400.

[13] Eisenmann, T., G. Parker, and M. Van Alstyne, "Platform Envelopment", Strategic Management Journal 32(12), 2011, pp. 1270-1285.

[14] Evans, D.S., and R. Schmalensee, Matchmakers: The New Economics of Multisided Platforms, Harvard Business Review Press, 2016.

[15] Foerderer, J., T. Kude, S. Mithas, and A. Heinzl, "Does Platform Owner's Entry Crowd Out Innovation? Evidence from Google Photos", Information Systems Research 29(2), 2018, pp. 444-460.

[16] Gawer, A., "Bridging Differing Perspectives on Technological Platforms: Toward an Integrative Framework", Research Policy 43(7), 2014, pp. 1239-1249.

[17] Gharajedaghi, J., and R.L. Ackoff, "Mechanisms, Organisms and Social Systems", Strategic Management Journal 5(3), 1984, pp. 289-300. 
[18] Griswold, A., “Amazon Abruptly Stopped Buying Goods from Third-Party Sellers", Quartz.

https://qz.com/1567934/amazon-sellers-panic-after-thecompany-reportedly-canceled-orders/. (accessed 2019-0715)

[19] Helfat, C.E., and M.A. Peteraf, "The Dynamic Resource-Based View: Capability Lifecycles", Strategic Management Journal 24(10), 2003, pp. 997-1010.

[20] Hofmann, D.A., "An Overview of the Logic and Rationale of Hierarchical Linear Models", Journal of Management 23(6), 1997, pp. 723-744.

[21] Holland, J.H., Emergence: From chaos to order, OUP Oxford, 2000.

[22] Johnson, R.A., F.E. Kast, and J.E. Rosenzweig, "Systems Theory and Management", Management Science 10(2), 1964, pp. 367-384.

[23] Keller, K.L., and D.R. Lehmann, "Brands and Branding: Research Findings and Future Priorities", Marketing Science 25(6), 2006, pp. 740-759.

[24] Kohli, R., and V. Grover, "Business value of IT: An essay on expanding research directions to keep up with the times", Journal of the association for information systems $9(1), 2008$, pp. 1.

[25] Littman, J., "Why the Delivery Market Will Look Different in 5 Years", Restaurant Dive, 2019. https://www.restaurantdive.com/news/why-the-deliverymarket-will-look-different-in-5-years/546936/

[26] Mcintyre, D.P., and A. Srinivasan, "Networks, Platforms, and Strategy: Emerging Views and Next Steps", Strategic Management Journal 38(1), 2017, pp. 141-160.

[27] Melville, N., K. Kraemer, and V. Gurbaxani, "Information technology and organizational performance: An integrative model of IT business value", MIS quarterly 28(2), 2004, pp. 283-322.

[28] Nevo, S., and M. Wade, "Firm-Level Benefits of ITEnabled Resources: A Conceptual Extension and an Empirical Assessment", The Journal of Strategic Information Systems 20(4), 2011, pp. 403-418.

[29] Nevo, S., and M.R. Wade, "The Formation and Value of It-Enabled Resources: Antecedents and Consequences of Synergistic Relationships.”, MIS Quarterly 34(1), 2010.

[30] Parker, G., M. Van Alstyne, and X. Jiang, "Platform Ecosystems: How Developers Invert the Firm”, MIS Quarterly 41(1), 2017, pp. 255+.

[31] Parker, G.G., M.W. Van Alstyne, and S.P. Choudary, Platform Revolution: How Networked Markets Are
Transforming the Economyand How to Make Them Work for You, WW Norton \& Company, 2016.

[32] Pavlou, P.A., and D. Gefen, "Building effective online marketplaces with institution-based trust", Information systems research 15(1), 2004, pp. 37-59.

[33] Piccoli, G., and B. Ives, "II-Dependent Strategic Initiatives and Sustained Competitive Advantage: A Review and Synthesis of the Literature", MIS Quarterly 29(4), 2005, pp. 747-776.

[34] Piccoli, G., and T.-W. Lui, "The Competitive Impact of Information Technology: Can Commodity IT Contribute to Competitive Performance?", European Journal of Information Systems 23(6), 2014, pp. 616-628.

[35] de Reuver, M., C. Sorensen, and R.C. Basole, "The digital platform: a research agenda", Journal of Information Technology 33(2), 2018, pp. 124-135.

[36] Setia, P., V. Sambamurthy, and D.J. Closs, "Realizing Business Value of Agile It Applications: Antecedents in the Supply Chain Networks", Information Technology and Management 9(1), 2008, pp. 5-19.

[37] Silver, M.S., and M.L. Markus, "Conceptualizing the Sociotechnical (ST) Artifact", Systems, Signs \& Actions 7(1), 2013, pp. 82-89.

[38] Tiwana, A., "Platform Synergy: Architectural Origins and Competitive Consequences", Information Systems Research 29(4), 2018, pp. 829-848.

[39] Tiwana, A., B. Konsynski, and A.A. Bush, "Platform Evolution: Coevolution of Platform Architecture, Governance, and Environmental Dynamics", Information Systems Research 21(4), 2010, pp. 675-687.

[40] Ulwick, A.W., "Turn Customer Input into Innovation.”, Harvard Business Review 80(1), 2002, pp. 91-7.

[41] Wade, M., and J. Hulland, "The Resource-Based View and Information Systems Research: Review, Extension, and Suggestions for Future Research", MIS Quarterly 28(1), 2004, pp. 107-142.

[42] Weick, K.E., The Social Psychology of Organizing, McGraw-Hill Humanities, Columbus, OH, 1979.

[43] Zhu, F., and Q. Liu, "Competing with complementors: An empirical look at Amazon.com”, Strategic Management Journal 39(10), 2018, pp. 2618-2642.

[44] "The Changing Market for Food Delivery", Mckinsey. https://www.mckinsey.com/industries/high-tech/ourinsights/the-changing-market-for-food-delivery. (accessed 2019-07-15) 